\title{
Novel Ceramic Additives for Screen-Printable Silicon Solar Cell Metallization
}

\author{
YU-CHOU SHIH, ${ }^{1,2}$ YUE SHAO, ${ }^{1}$ and FRANK G. $\mathrm{SHI}^{1}$ \\ 1.-Optoelectronics Packaging \& Materials Labs, Department of Chemical Engineering and \\ Materials Science, University of California Irvine, 916 Engineering Tower, Irvine, CA 92697, USA. \\ 2.-e-mail: yuchous@uci.edu
}

\begin{abstract}
The interfacial structure between front-side silver electrodes and $n$-type silicon emitters plays a very crucial role for the electrical and mechanical properties of silicon solar cells. Studies show that the residual glass layers at the $\mathrm{Ag} / \mathrm{Si}$ interfaces will significantly increase the contact resistance, and this subsequently leads to a decrease in the overall efficiency of the silicon solar cells. In this work, silver-coated nano-sized non-glass frits using an electroless plating method were employed to improve the interfacial conductivity. Transfer length method was applied to evaluate the electrical performance of the samples made with different ceramic additives. For samples made with nano-sized silver-coated ceramic additives, the improvement of conductivity was found to be about $22 \%$ compared to additives with the same compositions with no surface treatment. The results indicate that the silver layer on the surface of ceramic additives provides a conducting channel within the residual insulating layer and therefore reduces overall electrical resistance.
\end{abstract}

Key words: Nanoparticles, solar cells, electroless silver plating, TLM, interfacial structure, silver pastes

\section{INTRODUCTION}

Although there are other techniques such as photolithography and light-induced electroplating, which provide high quality silver electrodes, screen printing is still the most common technique used to form the front-side silver electrodes on silicon photovoltaic cells due to its cost- and time-effectiveness. ${ }^{1-4}$ Silver pastes used in screen printing primarily consist of three constituents including metal silver powders, micro-sized glass frits, and organic carriers. The purpose of adding glass frits is to etch through the $\mathrm{Si}_{3} \mathrm{~N}_{4}$ anti-reflection coating (ARC) layer above the $n$-type silicon layers and then silver and $n$-type silicon layers can form electrical conductive channels. Glass frits can also assist with formation of stable mechanical contacts between silver electrodes and silicon layers. Formulation of glass frits must be precisely controlled in order to provide sufficient mechanical adhesion of silver

(Received August 18, 2015; accepted May 5, 2016;

published online May 23, 2016) electrodes on silicon layers, while minimizing the internal stress that arises during the firing process and operation. High stress levels that have arisen from cells can lead to cracks and eventually fractures of the entire solar panel, and this issue is increasingly important while the solar photovoltaic (PV) industry is aggressively pushing the use of thin solar cells for cost reduction. ${ }^{5,6}$

After firing steps at above $700^{\circ} \mathrm{C}$, organic carriers are burned out and the residual glass constituents will form an electrically insulating layer at the interface between silver electrodes and the $n$-type silicon emitters, which results in high contact resistance at the $\mathrm{Ag} / \mathrm{Si}$ interfaces and subsequently lowers the overall efficiency of the silicon photovoltaic cells. It is evident that the composition of the glass frits, as well as the process conditions, should be well controlled to achieve a thin, discontinuous residual glass layer. ${ }^{1-4}$ Nano-sized non-glass frits have been proven to effectively reduce the thickness of the discontinuous residual glass layer due to their excellent etching ability, and specific contact 
resistivity between $\mathrm{Ag} / \mathrm{Si}$ interfaces of the samples made with nano-sized ceramic additives is only about $40 \%$ of that of the samples made with micronsized ones. ${ }^{3}$ Ceramic additives of smaller sizes possess larger surface areas, and therefore can achieve faster etching rates to remove the ARC layer with less material, which also reduces the firing duration and prevents the residual glass from experiencing accumulation at the $\mathrm{Ag} / \mathrm{Si}$ interfaces. The silver electrodes remain porous after the firing process and thus provide an escape route for nitrogen produced from the firing process. If the nitrogen cannot escape from the interface, it will either form a bubble, or react with the residual ceramic components and form the glass layer, and either result will introduce extra resistance to the $\mathrm{Ag} / \mathrm{Si}$ interfaces. Therefore, the use of nano-sized ceramic additives is beneficial in terms of electrical conductivity, which enhances the overall efficiency of the solar photovoltaic, and process duration, which reduces the cost and increases the production rate.

In this work, in order to further reduce the contact resistance at the $\mathrm{Ag} / \mathrm{Si}$ interfaces, nanosized ceramic additives with silver coating by the electroless plating method were employed to form the silver paste. Silver coating on the ceramic additives can prevent them from making direct contact with each other during and after the firing step. Even if a phase separation between the silver coating and ceramic substrates happens during the firing step, these two materials remain close to each other if the firing duration is very short. The electroless plating technique has attracted much attention in the semiconductor industries due to its low processing temperature, low overall cost, high coverage, and uniform coating. ${ }^{7-9}$ Moreover, electroless plating can deposit metals onto substrates with complex shapes and the process does not require a vacuum system. Coating coverage and thickness can be easily controlled by changing the processing parameters, such as activation time, plating duration, and $\mathrm{pH}$ value. Electroless silver plating has been well developed and applied to the deposition of metallic silver onto various substrates, such as micron-sized spheres and rods, nanoparticles, and glass substrate for microcontact. ${ }^{7-9}$ Different formulae were employed to investigate the effect of silver plating on the etching rate and the resultant specific contact resistivity. To avoid the complex interaction between different ceramic components at high firing temperatures, only $\mathrm{Bi}_{2} \mathrm{O}_{3}$, $\mathrm{Al}_{2} \mathrm{O}_{3}$, fused $\mathrm{SiO}_{2}$, and $\mathrm{ZnO}$ were used in this work, and the firing conditions including firing temperature and duration were the same as in our previous study. ${ }^{3}$ In order to maintain the function of ceramic additives, parameters of electroless plating were controlled to obtain a partial coverage of silver coating on the ceramic substrates. Transmission electron microscopy (TEM) and x-ray diffraction (XRD) were used to identify the silver deposition on the ceramic additives. Scanning electron microscopy
(SEM) was applied to investigate the $\mathrm{Ag} / \mathrm{Si}$ interfaces, and the results were compared with the electrical performance acquired by the transfer length method (TLM).

\section{EXPERIMENTAL}

All four nano-sized ceramic components used in this work are commercially available from Alfa Aesar. Table I summarizes the composition of the different silver paste formulae used in this work. The following procedure was used for the preparation of silver pastes: first, the appropriate amounts of solvent and polymer medium were well mixed and aged at $40^{\circ} \mathrm{C}$ for $24 \mathrm{~h}$. Silver powder, with an average size of $2 \mu \mathrm{m}$, was mixed with the abovediscussed organic medium and ceramic additives in a Thinky (Thinky USA) mixer for 4 min, followed by a de-airing for $10 \mathrm{~s}$. In order to ensure better mixing and to avoid agglomeration, the solid phase was added into the organic medium incrementally.

$\mathrm{AgNO}_{3}(99.95 \%)$ was obtained from Salt Lake Metals. Ethylenediamine and 3,5-diiodotyrosine were obtained from Sigma-Aldrich. Rochelle salt (potassium sodium tartrate) was obtained from Mallinckrodt Chemicals. Hydrochloric acid (36\%) and nitric acid was obtained from J.T. Baker. Stannous chloride dehydrate $\left(\mathrm{SnCl}_{2} \cdot 2 \mathrm{H}_{2} \mathrm{O}\right)$ was obtained from Alfa Aesar. All of these chemicals were used as received. The following procedure was used to form the electroless plating solution. First, the silver ion solution (denoted as solution A) and reducing agent solution (denoted as solution $B$ ) were prepared separately. Solution A is an aqueous solution composed of $\mathrm{AgNO}_{3}$ and ethylenediamine. Solution B is composed of Rochelle salt and 3,5diiodotyrosine in another aqueous solution. The two solutions were well mixed to form the electroless plating solution right before the silver plating step. The activation solution is composed of stannous chloride dehydrate and hydrochloric acid.

The procedure is as follows: first, the ceramic additives were poured into the activation solution to form the seed layer on the particle surface. Once the activation duration finished, the colloid was washed by isopropyl alcohol (IPA) twice and then centrifuged at $3000 \mathrm{rpm}$ for $15 \mathrm{~min}$. Once the supernatant was removed, water was added to form an aqueous solution for the next step. Solution A and B, as described above, were then mixed and the solution with ceramic additives was poured into this mixture for silver plating. During the plating, the $\mathrm{pH}$ value was controlled to be between 10.0 and 10.9 by diluted nitric acid. After the plating ended, the same washing and centrifuging were performed twice. After removing the supernatant, IPA was added to form a solution. This solution was then placed in an oven at $85^{\circ} \mathrm{C}$ to remove the solvent. Table II summarizes the experimental parameters in the electroless plating step. The resultant powder was used to form the silver pastes described above. 
The pastes were then screen-printed on $3 \mathrm{~cm} \times 1 \mathrm{~cm}$ and $200-\mu$ m-thick $n$-type $(100) \mathrm{Cz} \mathrm{Si}$ wafers with an 80-nm-thick $\mathrm{SiN}_{x}$ ARC layer on the top. For each silver paste used, six samples were made for measurement. TLM measurement was used to determine the specific contact resistivity under dark conditions. The pattern for TLM measurements is shown in Fig. 1a. Figure $1 b$ is the illustration showing the plotted TLM results for determining the specific contact resistivity of $\mathrm{Ag}$ electrodes. The specific contact resistivity $\left(\rho_{\mathrm{c}}\right)$ is obtained from extrapolating this linear plot of total resistance $\left(R_{\mathrm{T}}\right)$ versus the pattern grid spacing $(d) .{ }^{10}$

$$
\rho_{\mathrm{c}}=R_{\mathrm{c}} L_{\mathrm{t}} W
$$

where $R_{\mathrm{c}}$ is the contact resistance, $L_{\mathrm{t}}$ is the transfer length, and $W$ is the grid length.

The screen-printed wafers were then dried at $180^{\circ} \mathrm{C}$ for $15 \mathrm{~min}$ and then fired and sintered at $880^{\circ} \mathrm{C}$. The sintered wafers were tested by Agilent $4156 \mathrm{~A}$ to get the total resistance and the results were plotted according the TLM illustration shown above to determine the specific contact resistivity for these samples. Firing conditions and TLM results for different samples are summarized in Table III.

A transmission electron microscope (FEI/Philips CM-20 conventional TEM) and x-ray diffraction (Rigaku SmartLab x-ray Diffractometer) were used to identify the silver coating on ceramic additives. A scanning electron microscope (Philips XL-30 FEG
SEM) was used to investigate the microstructure at $\mathrm{Ag} / \mathrm{Si}$ interfaces.

\section{RESULTS AND DISCUSSION}

Figure 2 shows TEM images of $\mathrm{SiO}_{2}$ nanoparticles before and after electroless silver plating with a plating time of $10 \mathrm{~min}$. In Fig. $2 \mathrm{~b}$ there are small dots on the surface of $\mathrm{SiO}_{2}$ substrates. Figure 3 shows the comparison between pure $\mathrm{SiO}_{2}$ and $\mathrm{SiO}_{2}$ powder after $30 \mathrm{~min}$ of electroless silver plating. The plating time is prolonged to enhance the signal of silver plating. From the XRD patterns, $\mathrm{SiO}_{2}$ after plating shows signals of metallic silver. The peaks of $\mathrm{AgCl}$ indicate that there are residual chloride ions after the activation step. With TEM images and XRD patterns, silver coating on the surface of ceramic additives is confirmed.

The TLM results are summarized in Table III and Fig. 4 shows the boxplot of these results. Sample $\mathrm{N}-1$ consists of pure ceramic additives without any silver plating and this sample shows the intermediate specific contact resistivity among all different samples. For sample NE-2 with all four ceramic additives coated, because the silver coating actually blocks the contact between the etching agents $\left(\mathrm{Bi}_{2} \mathrm{O}_{3}\right.$ and $\left.\mathrm{ZnO}\right)$ and the $\mathrm{Si}_{3} \mathrm{~N}_{4}$ ARC layer, the etching rate of this paste is lowered and it takes a long time to remove the ARC layer and form the conducting channel at $\mathrm{Ag} / \mathrm{Si}$ interfaces. Sample NE-1 shows the lowest specific contact resistivity among all three types of samples. $\mathrm{Al}_{2} \mathrm{O}_{3}$ and $\mathrm{SiO}_{2}$

Table I. Composition (wt.\%) of silver pastes for different samples

\begin{tabular}{|c|c|c|c|c|c|c|c|}
\hline \multirow{2}{*}{$\begin{array}{l}\text { Sample } \\
\text { code }\end{array}$} & \multicolumn{5}{|c|}{ Ceramic additives } & \multirow[b]{2}{*}{ Silver } & \multirow{2}{*}{$\begin{array}{l}\text { Organic } \\
\text { medium }\end{array}$} \\
\hline & $\mathrm{Bi}_{2} \mathrm{O}_{3}(140 \mathrm{~nm})^{* *}$ & $\mathrm{Al}_{2} \mathrm{O}_{3}(45 \mathrm{~nm})^{* *}$ & $\mathrm{SiO}_{2}(80 \mathrm{~nm})^{* *}$ & ZnO $(70 \mathrm{~nm})^{* * *}$ & Total ceramics & & \\
\hline N-1 & 1.28 & 0.23 & 0.48 & 3.00 & 4.99 & 75.01 & 20 \\
\hline NE-1 & 1.28 & $0.23 *$ & $0.48^{*}$ & 3.00 & 4.99 & 75.01 & 20 \\
\hline NE-2 & $1.28^{*}$ & $0.23 *$ & $0.48^{*}$ & $3.00 *$ & 4.99 & 75.01 & 20 \\
\hline
\end{tabular}

*With electroless silver plating.**Average particle size.

Table II. Composition and process conditions of activation and plating solutions for electroless silver plating

\begin{tabular}{|c|c|c|c|}
\hline \multicolumn{2}{|c|}{ Activation solution } & \multicolumn{2}{|c|}{ Plating bath } \\
\hline Compound & Parameter & Compound & Parameter \\
\hline $\mathrm{SnCl}_{2} \cdot 2 \mathrm{H}_{2} \mathrm{O}$ & $2.1 \times 10^{-1} \mathrm{M}$ & $\mathrm{AgNO}_{3}$ & $3.0 \times 10^{-3} \mathrm{M}$ \\
\hline \multirow[t]{3}{*}{$\mathrm{HCl}(36 \%)$} & $3.4 \times 10^{-1} \mathrm{M}$ & Ethylenediamine & $1.8 \times 10^{-2} \mathrm{M}$ \\
\hline & & Rochelle salt & $3.5 \times 10^{-2} \mathrm{M}$ \\
\hline & & 3,5-Diiodotyrosine & $4.0 \times 10^{-5} \mathrm{M}$ \\
\hline $\mathrm{pH}$ & $9.5-10.2$ & $\mathrm{pH}$ & $10.0-10.9$ \\
\hline Temperature & $50^{\circ} \mathrm{C}$ & Temperature & $50^{\circ} \mathrm{C}$ \\
\hline Bathing time & $45 \mathrm{~min}$ & Bathing time & $3-30 \mathrm{~min}$ \\
\hline
\end{tabular}


(a)

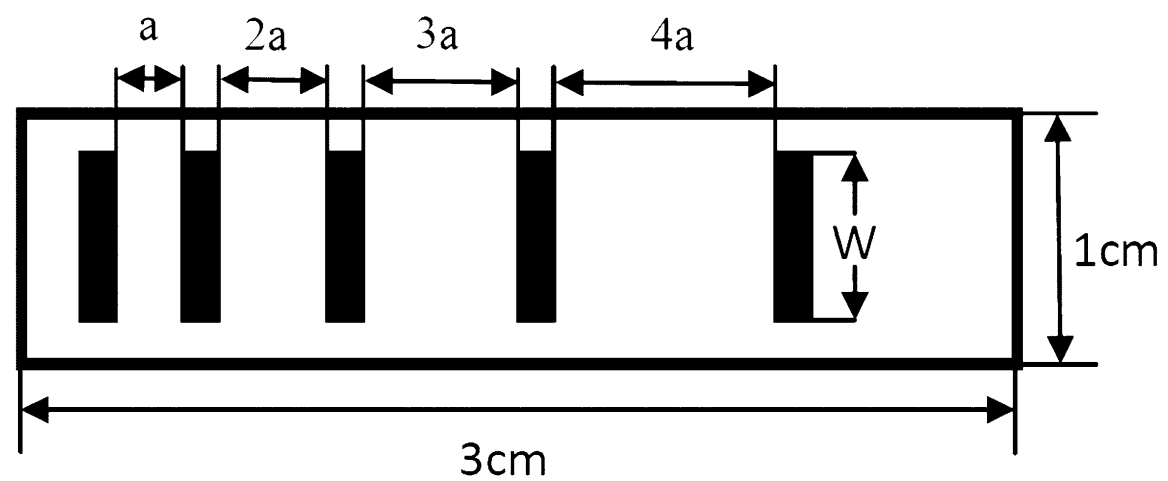

(b)

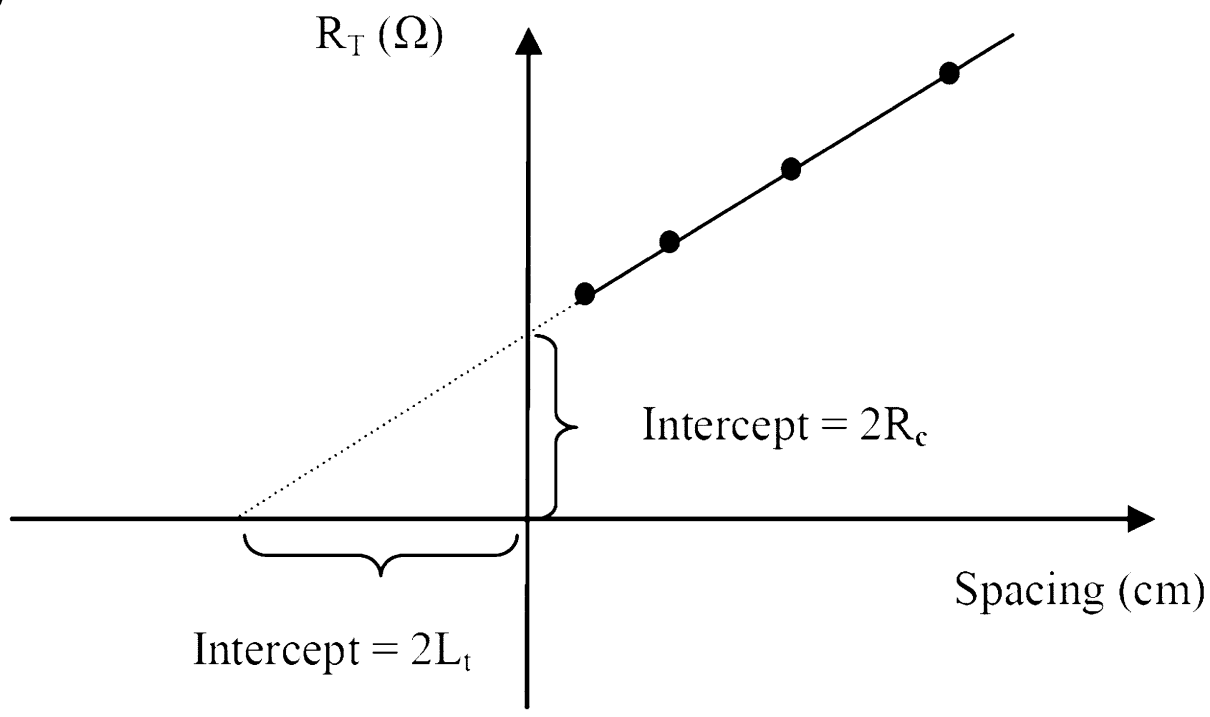

Fig. 1. The schematic graphs of (a) TLM pattern employed in this work. Here $a=0.25 \mathrm{~cm}$, and (b) the generic TLM result for determining the specific contact resistivity.

Table III. TLM results for tested samples

\begin{tabular}{|c|c|c|c|c|}
\hline Sample code & Total glass and oxide (wt.\%) & Firing conditions & Average $\rho_{c}\left(\Omega \mathrm{cm}^{2}\right)$ & Average $R_{c}(\Omega)$ \\
\hline $\mathrm{N}-1$ & 4.99 & $20 \mathrm{~s} / 880^{\circ} \mathrm{C}$ & 0.0140 & 2.19 \\
\hline NE-1 & 4.99 & $20 \mathrm{~s} / 880^{\circ} \mathrm{C}$ & 0.0109 & 1.70 \\
\hline NE-2 & 4.99 & $40 \mathrm{~s} / 880^{\circ} \mathrm{C}$ & 0.0221 & 3.45 \\
\hline
\end{tabular}
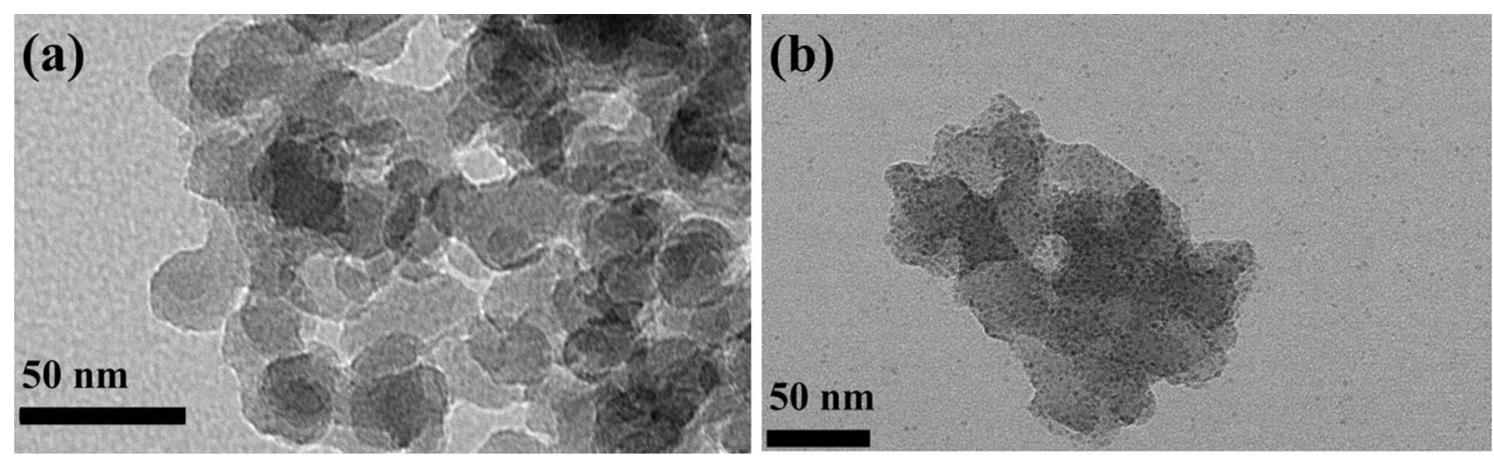

Fig. 2. TEM images of $\mathrm{SiO}_{2}$ nanoparticles used in this work: (a) pure $\mathrm{SiO}_{2}$ and (b) $\mathrm{SiO}_{2}$ powder with silver coating and 10-min plating time. 
can enhance the adhesion between the Ag electrodes and $n$-type silicon layers, but they are not the major etching agents. ${ }^{3}$ Therefore, silver coating on the surface of these two additives does not affect the etching rate through the ARC layers.

Figure 5 shows SEM images for three different types of samples. For Fig. 5a and b, the images look very similar but the glass clusters in Fig. 5a are larger. The difference in the size of residual glass

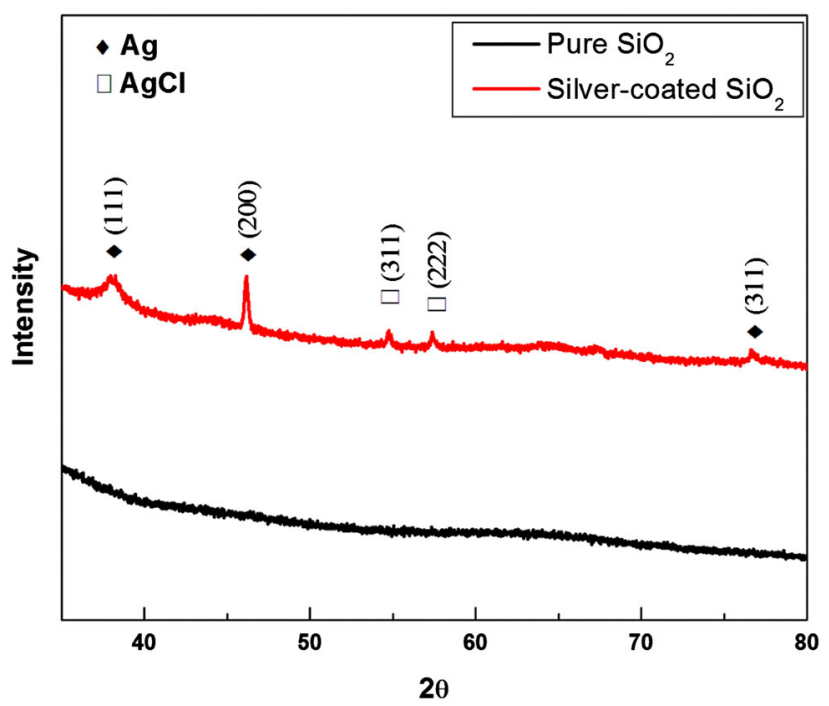

Fig. 3. Comparison of XRD patterns between pure $\mathrm{SiO}_{2}$ and silvercoated $\mathrm{SiO}_{2}$ with $30-$ min plating time. clusters indicates that the silver coating on the surface of the ceramic compositions can ensure the formation of discontinuous residual glass clusters, as well as a discontinuous glass layer at the $\mathrm{Ag} / \mathrm{Si}$ interfaces. Due to short firing duration, the pores and the large glass clusters near the interface can block the entire conducting route in the local section. Figure 5c shows a denser silver electrode because of the prolonged firing duration, which results in a longer time for the residual glass to accumulate at and cover most of the interface. However, because the silver electrode is denser and

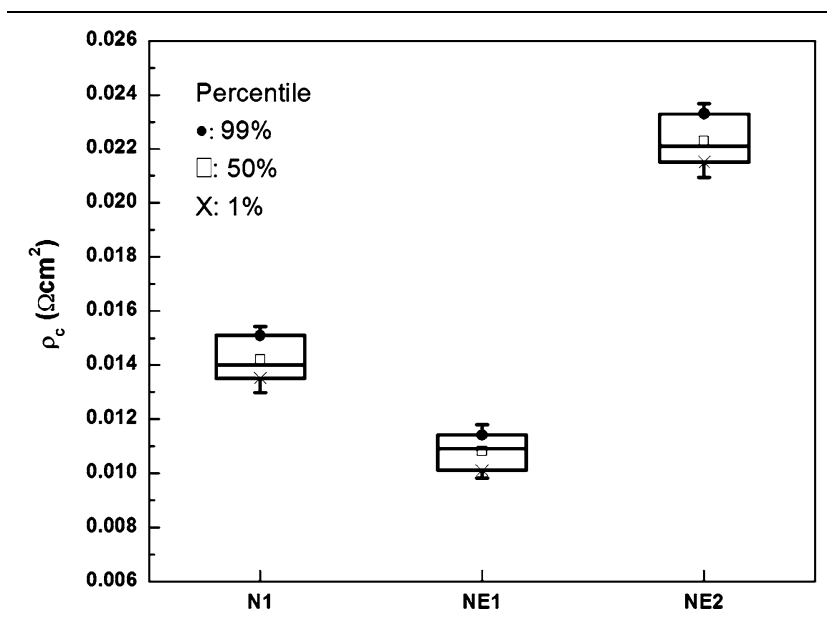

Fig. 4. Boxplot of TLM results for different tested samples. All tested samples have the same configuration as shown in Fig. 1 a.
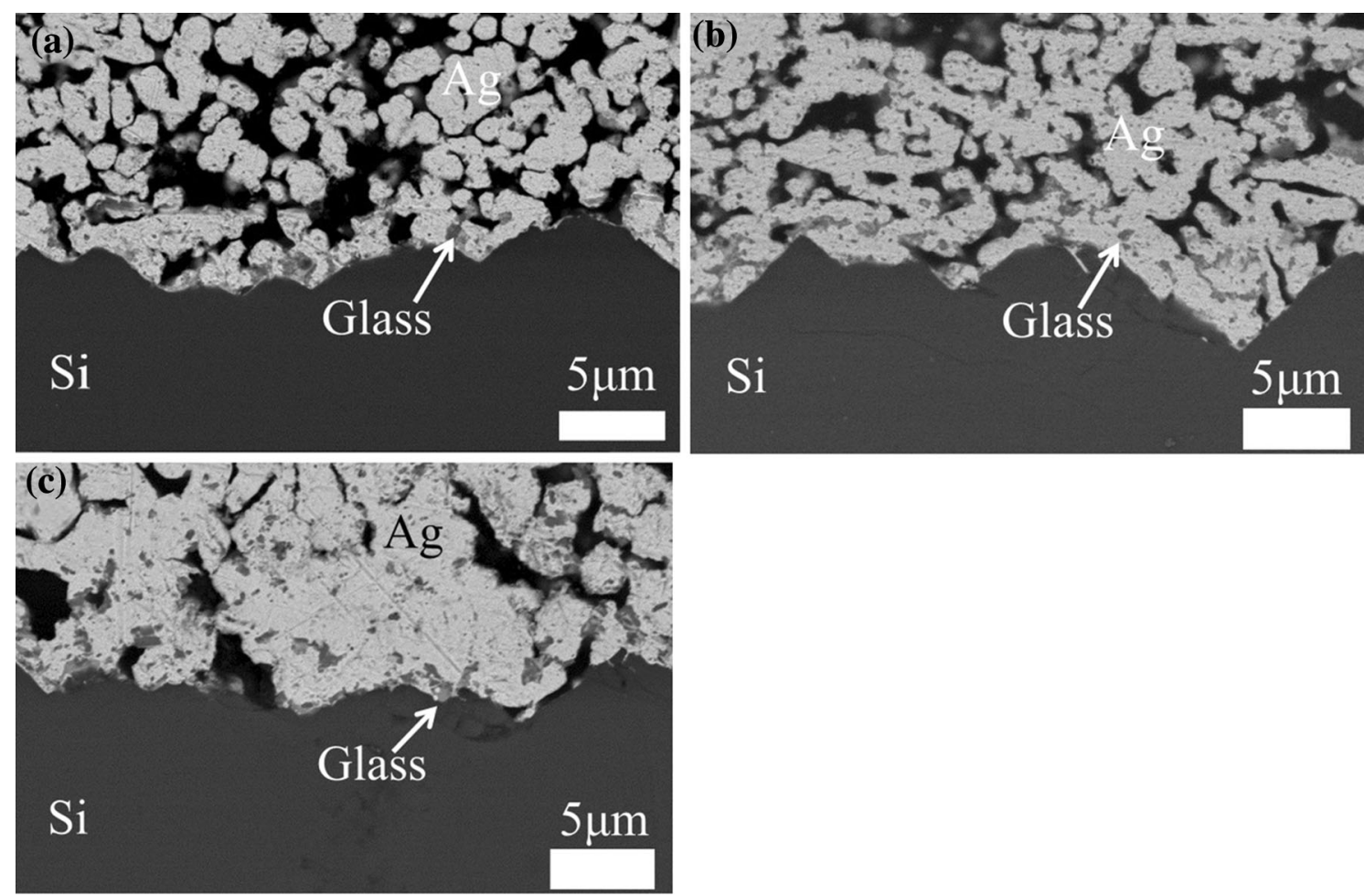

Fig. 5. SEM images of test samples made with (a) N-1, (b) NE-1, and (c) NE-2. 
all ceramic additives are accompanied by silver coating, the resultant specific contact resistivity is not much lower than the other two.

\section{CONCLUSION}

Nano-sized ceramic additives incorporated with silver coating by electroless plating was tested and compared with pure ceramic additives in terms of electrical performance. The results indicate that the formula consisting of silver-coated ceramic additives, as long as they are not the major etching agent, shows improved specific contact resistivity. Since low specific contact resistivity of the silver metallization contact is the most desirable property and is strongly affected by the interfacial microstructure and firing conditions, silver pastes with surface-modified ceramic additives are proven to possess a high etching rate of ARC layers, and subsequently form a desirable interfacial micro structure, which results in the preferable low specific contact resistivity. It is evident that with lower specific contact resistivity, the overall efficiency of silicon photovoltaic cells will be higher under otherwise identical conditions. The results of this present study demonstrate the importance of surface modification for chemical reactions, and also provide a new method for further enhancement in solar cell efficiency.

\section{REFERENCES}

1. Y. Zhang, Y. Yang, J. Zheng, G. Chen, C. Chen, J.C.M. Hwang, B.S. Ooi, A. Kovalskiy, and H. Jain, Thin Solid Films 518, e111 (2010).

2. S.B. Rane, T. Seth, G.J. Phatak, and D.P. Amalnerkar, J. Mater. Sci. Mater. Electron. 15, 103 (2004).

3. Y.C. Shih, Y.H. Lin, J.P. You, and F.G. Shi, J. Electron. Mater. 42, 410 (2012).

4. A.S. Ionkin, B.M. Fish, Z.R. Li, M. Lewittes, P.D. Soper, J.G. Pepin, A.F. Carroll, and A.C.S. Appl, Mat. Interfaces 3, 606 (2011).

5. A.S. Budiman, G. Illya, V. Handara, W.A. Caldwell, C. Bonelli, M. Kunz, N. Tamura, and D. Verstraeten, Sol. Energy Mater. Sol. C 130, 303 (2014).

6. Sascha Dietrich, Martin Sander, Matthias Pander, and Matthias Ebert, Proc. SPIE 8472, 84720P (2012).

7. C.H. Hsu, M.C. Yeh, K.L. Lo, and L.J. Chen, Langmuir 23 , 12111 (2007)

8. Y. Kobayashi, V. Salgueirino-Maceira, and L.M. LizMarzan, Chem. Mater. 13, 1630 (2001).

9. J. Choma, D. Jamiola, J. Ludwinowicz, and M. Jaroniec, Colloids Surf. A 411, 74 (2012).

10. D.K. Schroder, Semiconductor Material and Device Characterization, 2nd ed. (New York: Wiley, 1998), p. 156. 